\title{
MAKNA POPULARITAS DALAM LIRIK LAGU “THE LUCKY ONE” KARYA TAYLOR SWIFT: SEBUAH ANALISIS SEMIOTIKA
}

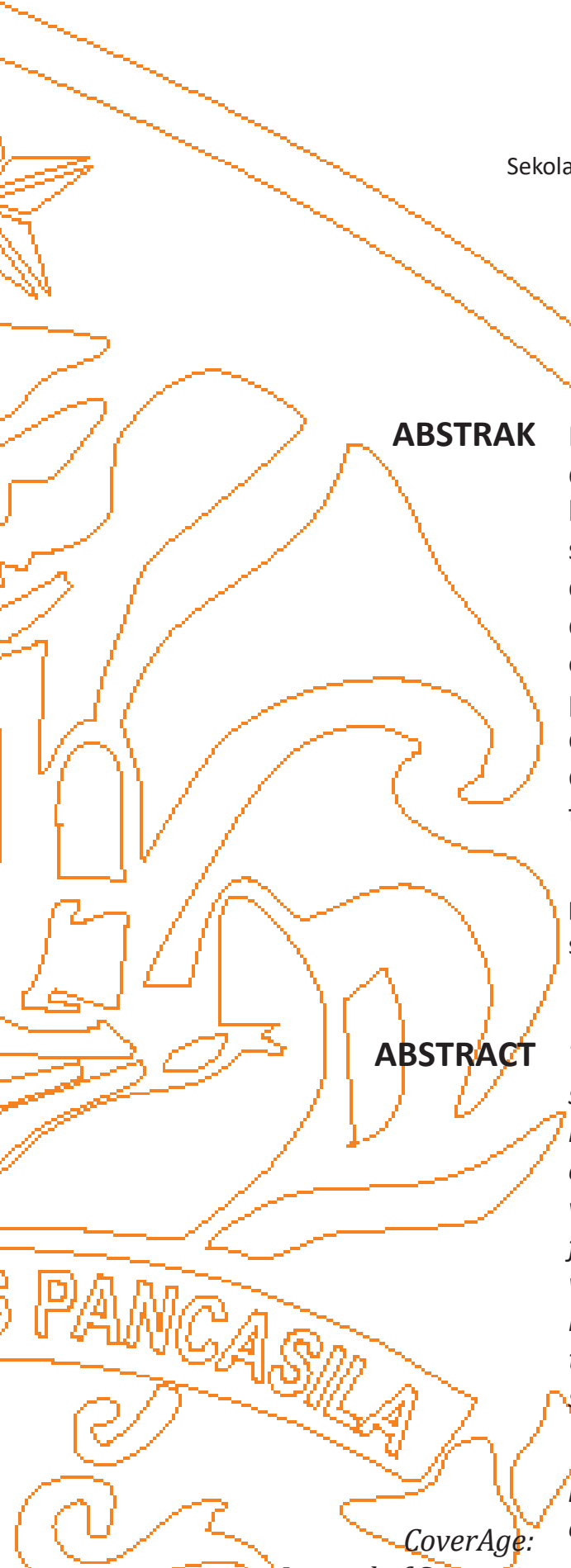

\author{
QILAN UMARA RIDWAN
}

Sekolah Tinggi Ilmu Komunikasi, London School of Public Relations Email: qilannumaraa@gmail.com

Kata Kunci: Lirik lagu "The Lucky One”, makna popularitas, semiotika ferdinand de saussure.

Penelitian ini bertujuan untuk menemukan makna penanda (signifier) dan petanda (signified), sintagmatik dan hubungan signification dari lirik lagu. Metode yang digunakan adalah kualitatif dengan pendekatan analisis semiotika interpretatif atau konstruktivisme. Kesimpulan dari hasil yang ditemukan adalah, ada berbagai arti popularitas berdasarkan kalimat yang dianalisis yaitu, ketenaran, kemewahan, publikasi, kekayaan, perasaan optimis, cantik dan keren, dipuja, dianggap beruntung tapi pada akhirnya perasaan berubah, merasa dimanfaatkan, dapat tergantikan, bingung, sepi dan tidak beruntung. Saran untuk penelitian selanjutnya untuk eksplor lebih dalam bagian sinkronik dan dikronik dari bahasa yang digunakan dalam lagu tersebut.

This study aims to find the meaning of the signifier and the signified, syntagmatic and the relationship of signification of the song lyrics. The method used is qualitative with an interpretive semiotic analysis approach or constructivism. The conclusion from the results found is, there are various meanings of popularity based on the sentences analyzed namely, fame, luxury, publication, wealth, optimistic feelings, beautiful and cool, worshiped, considered lucky but in the end feelings change, feel used, can be replaced, confused, lonely and unlucky. Suggestions for further research to explore deeper synchronous and chronic parts of the language used in the song.

Keywords: Song lyrics "the lucky one", meaning of popularity, semiotics ferdinand Journal of Strategic Communication Vol. 9, No. 1, Hal. 45-52. September 2018 Fakultas Ilmu Komunikasi, Universitas Pancasila 


\section{PENDAHULUAN}

Taylor Swift lahir pada tanggal 13 Desember 1989 di Pennsylvania. Taylor sudah bernyanyi di festival musik sejak ia berusia 9 tahun. Taylor meraih juara pada ajang lomba pencari bakat lokal, pada usia 11 yang memberinya kesempatan untuk tampil sebagai pembuka untuk penyanyi Charie Daniels. Kemudian ketika ia berusia 14 tahun Taylor dan sekeluarga memutuskan untuk pindah ke Nashville, Tennessee untuk meneruskan karirnya di bidang musik. Taylor Swift adalah menggabungkan musik country dan pop. (Djajengminardo dan Santi, 2013: 15-17).

Sebagai penulis lagu, dia telah diberi penghargaan oleh Nashville Songwriters Association dan Songwriters Hall of Fame. Taylor Swift telah dinominasi sebanyak 541 kali dan memenangkan 250 dari penghargaan bergengsi (Noverina, 2015:12-18)..

Taylor Swift yang terkenal dengan lagu percintaan yang ia ciptakan, ada pengalaman yang berbeda yang ia ciptakan dalam sebuah lagu, dalam lagu "The Lucky One" Taylor membicarakan bukan tentang pecintaan. Pada penelitian ini, peneliti bermaksud untuk membahas tentang pesan apa yang Taylor sampaikan melalui lagu tersebut. Peneliti berasumsi bahwa Taylor Swift ingin membagi makna popularitas di dalam lirik lagu tersebut. KBBI mendefinisikan popularitas sebagai perihal popular; kepopuleran, sesuatu atau seseorang yang dikenal dan digemari orang banyak. Lirik "The Lucky One" sebagai berikut :

New to town with a made up name in the angel city, Chasing fortune and fame

And the camera flashes, make it look like a dream You had it figured out since you were in school Everybody loves pretty, everybody loves cool So overnight you look like a sixties' queen Another name goes up in lights, like diamonds in the sky

And they'll tell you now, you're the lucky one Yeah, they'll tell you now, you're the lucky one But can you tell me now, you're the lucky one Now it's big black cars, and Riviera views And your lover in the foyer doesn't even know you And your secrets end up splashed on the news front page

And they tell you that you're lucky
But you're so confused

Cause you don't feel pretty, you just feel used And all the young things line up to take your place It was a few years later, I showed up here And they still tell the legend of how you disappeared How you took the money and your dignity, and got the hell out

They say you bought a bunch of land somewhere Chose the Rose Garden over Madison Square And it took some time, but I understand it now 'Cause now my name is up in lights,

But I think you got it right

Let me tell you now, you're the lucky one Let me tell you now, you're the lucky one Let me tell you now, you're the lucky one, oh, oh, oh And they'll tell you now, you're the lucky one Yeah, they'll tell you now, you're the lucky one And they'll tell you now, you're the lucky one, oh, oh, oh

Oh, whoa, oh

\section{TINJAUAN PUSTAKA}

\section{Semiotika Ferdinand de Saussure}

Semiotika Saussure adalah sebuah sistem tanda di mana setiap tanda itu disusun menjadi dua bagian yakni signifier dan signified. Signifier berartikan penanda dan signified berartikan petanda. Tanda adalah apa yang dihasilkan dari asosiasi penanda dan petanda. Hubungan antara penanda dan petanda tersebut yang disebut sebagai signifikasi. Penanda sendiri adalah medium yang diambil oleh suatu tanda seperti bunyi, gambar atau coretan membentuk kata di suatu halaman. Sedangkan makna dan konsep adalah apa yang disebut petanda. Tanda dalam teori Saussure adalah apa yang disebut sebagai Bahasa. Bahasa terdiri dari langue (bahasa sesuai kaidah) dan parole (bahasa yang berkembang) kemudian diklarifikasikan ke sinkronis (langue) dan diakronis (parole). Sebuah kalimat juga dikaji melalui hubungan Sintagmatik atau Paradigmatik. Keseluruhan tersebut adalah kunci untuk mengkaji sebuah bahasa yang kemudian akan menghasilkan sebuah makna (Hidayat,1988: 4-20).

\section{Pengertian Popularitas}

Untuk menganalisis makna juga perlu diketahui arti dari popularitas, menurut Williams, budaya 
populer adalah bahwa kedua kata tersebut adalah sebuah kata gabungan. "Budaya" dan yang satunya lagi "Populer". Di mana, budaya diartikan sebagai "segala sesuatu untuk mengacu pada suatu proses umum perkembangan intelektual, spiritual dan estetis" (Williams,1983:90).

Williams memberikan empat arti terhadap istilah kata "pop" yang diambil dari kata "populer" sebagai kata yang memiliki makna di antaranya: (Williams, 1983: 23-70)

1. Banyak disukai orang

2. Jenis kerja rendahan

3. Karya yang dilakukan untuk menyenangkan orang

4. budaya yang memang dibuat oleh orang untuk dirinya sendiri

Ciri Ciri popularias dirangkum pada jurnal Analisa Gaya Hidup Remaja Dalam Mengimitasi Budaya Pop Korea Melalui Televisi. Di antaranya adalah: (Kaparang, 2013)

1. Tren

2. Keseragaman Bentuk

3. Adaptabilitas

4. Durabilitas

5. Profitabilitas

\section{METODE}

Metode penelitian yang digunakan adalah kualitiatif dengan paradigma konstruktivis. Dalam praktiknya peneliti yang menggunakan pendekatan kualitatif kontruktivisme maka akan membuat interpretasi atau penafsiran tentang apa yang ditemukan dipengaruhi oleh pengalaman dan latar belakang yang diteliti." (Cresswell, 2015: 33).

\section{HASIL DAN PEMBAHASAN}

Penanda adalah sebuah konsep dari objek, maka pada penelitian ini, konsep adalah berupa keseluruhan dari lirik lagu "The Lucky One" karya Taylor Swift. Makna penanda dari lagu sebagai. Maka petanda (signifier) dari lagu "The Lucky One" karya Taylor Swift adalah konsep dari makna lirik lagu, konsep tersebut adalah yang disebut keseluruhan lirik lagu dan pada penelitian ini adalah keseluruhan dari lirik lagu.

\section{Makna Signified (Petanda)}

Tanda popularitas pada bait I dapat dilihat pada baris ke dua hingga kelima, "Chasing fortune and fame" yang berarti mengejar kekayaan dan ketenaran. Menjadi seseorang yang populer dapat memberikan kesempatan yang besar untuk menghasilkan profit yang besar. Menurut KBBI kata "ketenaran" yang berasal dari kata "tenar". Kata tenar memiliki arti, sesuatu atau seseorang yang diketahui orang banyak. Selain itu ada kata kekayaan juga di dalam kalimat yang mengacu kepada keuntungan profit.

Menurut Kaparang (2013) kalimat di atas memilki ciri-ciri popularitas di dalamnya yaitu profitabilitas karena ada unsur keuntungan profit di dalamnya. Lalu tanda popularitas juga dapat dilihat pada baris kedua yaitu "And the camera flashes, make it look like a dream" memiliki arti dan kamera berkilatan, membuat semua terasa mimpi. Pada baris ini, terdapat makna popularitas di dalamnya yaitu "disenangi banyak orang". Kata kamera pada kalimat ini menunjukan bahwa banyak orang yang ingin melihatnya dan menjadi sorotan publik. Potret diri disebuah konten produksi massa yang dihasilkan dari sebuah kamera menjadi konsumsi publik secara luas.

Alasan dirinya menjadi sebuah konten media massa adanya efek dari minat masyarakat terhadap dirinya, seseorang yang disenangi akan cenderung menjadi konsumsi yang diminati. Banyaknya yang menkonsumsi dan mengadopsi produk atau hasil karya dari seorang yang populer dan pada kasus ini adalah publik figur. Maka, pada kalimat tersebut terdapat kalimat yang memiliki makna mengacu kepada banyak orang mengadopsi produk atau hasil karya.

Menurut Kaparang (2013) kalimat yang memiliki ciri-ciri di mana sebuah budaya diadopsi dan dinikmati banyak orang maka kalimat tersebut memiliki ciri-ciri popularitas yang mengacu kepada adaptabilitas. Kemudian dilanjutkan kembali kepada lirik pada baris keempat hingga keenam. "You had figured out since you were in school" yang memiliki arti, kau telah tahu sejak kau masih sekolah. "Everybody loves pretty, everybody loves cool". yang memiliki arti semua orang suka yang cantik, semua orang suka yang keren.

"So overnight you look like a sixties' queen" yang memiliki arti maka dalam semalam kau tampak seperti ratu tahun enam puluhan. Pada kalimat-kalimat tersebut peneliti menemukan tanda 
popularitas di dalamnya yaitu, makna nya disukai banyak orang di mana ketika lirik menyebutkan semua orang menyukai yang cantik dan keren dan keinginan untuk berubah menjadi ratu 60an, disitu letak makna popularitas. Di mana seseorang yang dapat terus menjadi unik tidak akan tergantikan oleh waktu dengan yang lainnya. Semua yang populer, tidak akan selalu ada di atas, pastinya jika mereka tidak bisa menjaga ketenarannya, mereka dapat tergantikan dengan orang yang baru. Karena semua orang suka yang cantik dan keren, dengan perkembangan waktu, pasti akan selalu orang yang lebih cantik dan lebih keren dari yang sebelumnya.

Seperti yang ada pada kalimat selanjutnya adalah "Another name goes up in lights, like diamonds in the sky" pada bait II (Pre Chorus) yang artinya adalah nama baru bersinar, seperti berlian di langit. Pada kalimat ini juga mencerminkan durabilitas di mana, pada akhirnya semua akan tergantikan oleh waktu dan hanya yang dapat bisa memepertahankan eksistensi yang dapat bertahan, kalau tidak, akan selalu ada nama baru datang untuk bersinar.

Kalimat-kalimat di atas memiliki makna bagaimana seseorang dapat mempertahankan keeksistesian dirinya dan tidak dapat tergantikan oleh orang lain karena seseorang yang populer dapat tergantikan oleh waktu.

Menurut apa yang dinyatakan Kaparang (2013) pada ciri ciri popularitas, kalimat-kalimat di atas yang memiliki makna bagaimana seseorang bertahan dan tidak dilupakan oleh waktu, memiliki ciri popularitas yaitu durabilitas yang mengacu kepada durasi seseorang yang dapat bertahan.

Makna dari tanda popularitas yang terdapat pada chorus dalam bait III, ada pada kalimat "And they'll tell you now, you're the lucky one", yang artinya adalah dan mereka kan memberitahumu bahwa kau orang yang beruntung. Pada kalimat ini terdapat pengungkapan perasaan beruntung setelah dapat mengejar sebuah kekayaan, ketenaran dan keindahan yang telah dijelaskan di bait sebelumnya. Pada dasarnya rasa beruntung adalah perasaan yang relatif, untuk kaum populer mereka merasa beruntung ketika karya nya dapat memberi kesenangan bagi orang banyak, maka mereka dapat merasa beruntung untuk dapat mencapai kesuksesan tersebut. Maka dari itu, pada bait ini, terdapat makna popularitas di dalamnya. Pada bait ini terdapat makna di mana sesuatu karya yang sukses di senangi banyak orang.
Menurut Williams (1983) kalimat-kalimat di atas yang terdapat makna popularitas di dalamnya yaiitu "karya yang dibuat untuk menyengangkan banyak orang".

Lalu, dilanjutkan dengan baris ke empat dalam bait III dapat terlihat tanda popularitas pada penyebutan mobil hitam besar dengan pemandangan reviera. "Now it's big black cars, and Riviera views" (Kini mobilmu hitam besar, dan pemandangan Riviera). Di sini dapat dilihat, unsur kemegahan dan kekayaan yang dimiliki seseorang yang sudah menjadi populer. Dengan popularitas, seseorang dapat membuahkan profit yang besar, mengacu pada profitabilitas.

Selain itu, pada baris ke enam, ketika lirik mengatakan "and your secrets end up splashed on the news front page" (dan rahasiamu terkuak di halaman depan koran). Masyarakat telah mengadaptasi artis dengan melihat gaya hidup dan cerita kehidupannya. Maka dari itu tidak heran mengapa seseorang yang sudah menjadi sorotan publik, dikenal dan disukai banyak orang. Dapat tersebar rahasianya di media cetak koran. Menurut Kaparang (2013) sesuatu yang dikenal dan disukai banyak orang adalah hal yang memiliki ciri-ciri popularitas di dalamnya. Pada hal ini, kalimatkalimat di atas dapat mengacu kepada ciri-ciri popularitas yaitu adaptabilitas.

Selanjutnya adalah bait ke IV memiliki tanda popularitas pada baris kedua, ketiga hingga keempat yang berbunyi "you're so confused" (Tapi kau sangat bingung). "Cause you don't feel pretty, you just feel used" (karena kau tak merasa cantik, kau hanya merasa dimanfaatkan) "And all the young things line up to take your place". (Dan artis-artis muda antri ingin menggantikan tempatmu).

Kalimat yang menjelaskan perasaan "tak merasa cantik, hanya merasa dimanfaatkan" adalah perasaan sebuah karya yang dibuat untuk menyenangkan orang banyak. Namun, ternyata terdapat perasaan dimanfaatkan. Menjadi cantik dan terlihat anggun adalah perbuatan yang dapat menyenangkan orang banyak. Yang kemudian banyak artis-artis muda ingin menggantikan tempat. Banyaknya orang yang ingin menggantikan posisi.

Kalimat-kalimat ini menjelaskan bahwa suatu karya yang disukai banyak orang, diadopsi, diikuti dan banyak yang ingin menggantikan posisi seseorang yang sudah populer.

Pada penjelasan di atas menurut Kaparang (2013) kalimat-kalimat di atas menunjukan 
ciri-ciri popularitas di antaranya sudah terjadi tren dan adaptabilitas. Kemudian berdasarkan analisis di atas, menurut Williams (1983) kalimat di atas percaya bahawa kalimat di atas memiliki keseragaman bentuk dan budaya yang telah diciptakan sebelumnya ingin diraih untuk kepentingan diri sendiri.

Di sini lagu bercerita bagaimana banyak dari masyarakat yang telah teradaptasi dengan budaya yang ada. Ingin menggapai cita-citanya menjadi publik figur. Menjadi seorang yang populer. Karena popularitas adalah budaya pop yang datang untuk memberikan keuntungan bagi banyak orang. Juga banyak yang ingin menggantikan mengacu pada durabilitas.

Tanda popularitas yang terdapat pada Bait V hingga IX ada pada kalimat "How you took the money and your dignity and got the hell out" di bait ke $\mathrm{V}$ baris ketiga yang artinya adalah (Bagaimana kamu membawa uang dan kehormatanmu dan pergi begitu saja). Ada penyebutan kata uang pada kalimat ini mengacu kepada sebuah profit.

Menurut Kaparang (2013) bahwa sesuatu yang menguntungkan sebuah profit memiliki ciri-ciri popularitas. Maka pada kalimat ini menurut terdapat ciri popularitas yaitu profitabilitas.

Karya yang diciptakan lalu masyarakat menghormati karyanya. Lalu dilanjutkan dengan bait ke VII pada baris awal "Cause my name goes up in lights" yang memberikan arti "karena kini nama ku bersinar" memberikan tanda popularitas yang sama seperti "disenangi banyak orang". Kemudian di bait akhir memiliki tanda popularitas yang sama dengan chorus bait III.

Menurut Williams (1983) yang disenangi banyak orang adalah hal yang mengacu kepada sesuatu yang memiliki makna popularitas. Maka pada kalimatkalimat pada bait-bait di atas terdapat makna popularitas di dalam kalimat tersebut.

Lalu kalimat pada bait VIII "and let me tell you now you're the lucky one" yang memiliki arti "biar kukatakan padamu, bahwa kau orang yang beruntung". namun makna beruntung dalam kalimat ini cenderung kepada para masyarakat biasa yang mendengarkan lagu dan bukan terhadap si penulis lagu atau kaum populer.

Williams (1983) mengatakan bahwa suatu budaya akan disebut sebagai budaya populer jika karyanya disenangi banyak orang. Lalu pada kalimat di atas memiliki makna tersebut yang serupa dengan bait ke III dan memiliki makna dan penjelasan sama.

\section{Makna Sintagmatik}

Makna sintagmatik akan dibagi menjadi beberapa paragraf yang memiliki tanda popularitas sesuai dengan apa yang sudah dilakukan pada tahap analisis makna signified.

\section{Makna Sintagmatik Pada Bait I - Pre-chorus}

Pada bait ini, makna dari tanda popularitas yang ingin disampaikan adalah tentang perjalanan untuk mendapatkan kekayaan dan ketenaran. Jika kita melihat kalimat pertama yang memiliki tanda popularitas dimulai dengan kata "Mengejar". Kata mengejar menurut KBBI adalah tindakan menangkap dan memburu. Lalu ketika kata tersebut digabungkan menjadi sebuah kalimat berbunyi "Mengejar kekayaan dan ketenaran", maka terdapat makna yang berbeda. Dari hanya menggapai hingga telah memiliki misi dan tujuan yang akan digapai.

Lalu dilanjutkan dengan kalimat yang dimulai dengan kata "lampu". Lampu menurut KBBI adalah alat yang menerangkan. Namun jika kalimat tersebut digabungkan dengan kata lain menjadi "Lampu kamera yang berkilatan, membuat semua terasa mimpi". Kemudian lampu tersebut akan berubah makna nya, menjadi sebuah alat dalam kamera yang dapat memanipulasi kenyataan, karena terdapat kata "mimpi" dikalimat tersebut, karena menurut KBBI kata "mimpi" adalah sebuah angan-angan atau sesuatu yang dicita-citakan.

Kalimat selanjutnya adalah "Kau telah tahu sejak kau masih sekolah, semua orang suka yang cantik, semua orang suka yang keren, maka dalam semalam kau tampak seperti ratu tahun enam puluhan." Subjek dalam kalimat ini adakah kau. Dan fokus dari kalimat ini adalah cantik dan keren. Kau adalah kata lain dari kata kamu yang berarti adalah orang yang lain yang dituju orang penulis kata "kau". Menurut KBBI kata cantik adalah dan keren adalah sesuatu yang indah dan bagus. Kata-kata yang mengacu kepada keindahan fisik. Makna dari setiap kata tersebut dilengkapi dengan uraian kata yang di atas. Kemudian memberikan makna bahwa seseorang tahu sejak dulu bahwa tampil bagus akan disukai orang, maka perubahan diperlukan. Terdapat pada kalimat dalam pre-chorus yang berbunyi "Nama baru bersinar, seperti berlian di langit".

Ketika kita membaca kata "nama", nama menurut $\mathrm{KBBI}$ adalah kata untuk menyebut sesuatu atau seseorang. Namun, ketika kata 
nama disambungkan dengan kata bersinar dan berlian. Maka kalimat tersebut memiliki makna yang berbeda. Nama yang adalah sebuah sebutan kemudian memiliki arti yaitu, makna yang bersinar dan dalam konteks ini adalah bersinar layaknya artis ternama. Seperti artis di Amerika serikat.

\section{Makna Sintagmatik Pada Bait ke III-IV}

Kata "beruntung" dalam kalimat awal digabungkan dengan kata "kamu" yang memberikan makna bahwa "kamu adalah orang yang beruntung". Beruntung adalah sebuah anugerah dan di sempurnakan dengan kata kamu agar memberikan makna bahwa si "kamu" tersebut mendapatkan sebuah anugerah yaitu keberuntungan.

Menurut KBBI, Mobil adalah kendaraan darat dengan tenaga mesin beroda empat beroda empat, namun jika kata tersebut disandingkan dengan "kini mobilmu hitam besar dan pemandangan riviera" yang memberikan esensi kemewahan. Kata mobil dalam kalimat ini akan memberikan makna yang berbeda, yaitu makna kekayaan dan kemegahan juga kehidupan yang mewah. Kemudian, dalam kalimat tersebut berbunyi "Rahasiamu terkuat di halaman depan koran".

Menurut KBBI rahasia adalah sesuatu yang disembunyikan agar orang lain tidak tahu, dan koran yang memiliki lembaran-lembaran kertas berita. Ketika kedua ketika tersebut disandingkan, kalimat dapat memberikan makna yang berbeda.

Rahasia adalah cerita yang seseorang miliki dan tidak diketahui siapapun melainkan orang tersebut. Namun dalam kalimat di atas, rahasia dapat menjadi makna yang berbeda karena rahasia terkuak dihalaman depan koran. Maka rahasia dapat menjadi berita hangat.

Lalu dilanjutkan dengan kata "bingung" pada bait IV dengan kalimat yang berbunyi "Tapi kau sangat bingung, karena kau tak merasa cantik, kau hanya merasa dimanfaatkan." Menurut KBBI kata bingung mengacu kepada perasaan yang tidak tahu arah dan kurang jelas, pada kalimat ini kata bingung yang berarti adalah perasaan yang berubah-ubah dapat disadingkan dengan kata dimanfaatkan. Maka makna bingung yang awalnya adalah perassaan yang dilematik, dapat berubah dengan perasaan pasti yaitu dimanfaatkan.

\section{Makna Sintagmatik pada bait V-IX}

Pada kalimat "Bagaimana kamu membawa uang dan kehormatanmu dan pergi begitu saja" fokus dalam kalimat tersebut ada pada kata uang. Menurut KBBI, kata uang adalah alat tukar dapat berupa kertas ataupun koin. Uang hanyalah kata benda yang berarti nilai tukar. Namun jika disandingkan dengan kata-kata lain di atas, maka kata uang dapat berubah makna menjadi sebuah kata benda yang berharga seperti sebuah kehormatan. Kehormatan dan kekayaan dapat kembali lagi dengan budaya Amerika yang mengutamakan keberhasilan. Kalimat "karena kini namaku bersinar" memiliki makna sama dengan pre chorus.

Kemudian dilanjutkan dengan kalimat "Biar kukatakan padamu bahwa kau orang yang beruntung. Pada kalimat "biar kukatakan padamu bahwa kau orang yang beruntung" terdapat bahasa yang dianalisa dengan berbeda yaitu paradigmatik, karena pada kalimat ini terdapat makna yang sama dengan tanda yang berbeda. Kalimat ini telah dikatakan sebelumnya dan memiliki makna bahwa masyarakat luas menganggap bahwa para artis yang populer adalah orang yang beruntung dan memiliki makna popularitas "karya yang dibuat untuk menyenangkan banyak orang" Namun pada kalimat ini, subjek berubah menjadi artis menganggap bahwa masyarakat biasa lah yang beruntung. Sebuah kalimat dapat dilihat sebagai sudut pandang paradigmatik di mana kalimat tersebut dapat tergantikan dengan subjek yang lain namun tetap memiliki makna yang sama.

Paradigmatik adalah hubungan yang saling menggantikan, ketika kalimat menyatakan 'Kucing berbaring di atas kasur' maka kata kucing dapat diganti dengan singa atu anjing namun kalimat harus tetap dalam wujud yang sesuai dengan aturan bahasa, yaitu sintagmatiknya.

\section{Makna Signification}

Dimulai dari Bait I tentang lampu kamera yang menjelaskan bahwa dalam perjalanan tersebut seseorang dalam kisah itu adalah sorotan publik. Hingga kepada kalimat yang menjelaskan bahwa masyarakat menyukai yang keren dan cantik, mengingatkan kepada opini masyarakat yang menyatakan bawha semua orang sejak masih sekolah beropini bahwa yang cantik dan yang keren adalah yang disukai maka dari itu untuk menggapai sebuah mimpi tersebut, diperlukan 
proses transformasi yang instan berubah menjadi seseorang yang cantik dan keren seperti ratu tahun $60 a n$. Namun, tidak dipungkiri bahwa waktu dapat merubah segalanya dan menggantikan seseorang yang sudah menjadi sorotan publik dengan orang lain. Cerita dalam lagu ini dapat menjadi pengaruh dari budaya yang ada di Amerika.

Menurut Mulyana (2007) Amerika memiliki budaya komunikasi yang yang low-contex, di mana, masyarakat Amerika bebas berkespresi bahkan sejak usia sekolah. Menurut Nafisah (2014) media massa berperan penting dalam penyebaran budaya populer yang datang dari Amerika Serikat. Di antaranya adalah tontonan media massa yang menyoroti kehidupan bintang hollywood, pemotretan di red carpet dan sebagainya, seakan menjadi berita yang masyarakat kususnya kaum remaja di Amerika lihat sehari-harinya.

Hc Indonesia (2015) menyantumkan dalam situsnya bahwa industri seni sangat berkembang di Amerika Serikat, seperti broadway di New York yang sudah menjadi sorotan dunia. Budaya populer juga sudah menjadi pola pikir masyarakat dikarenakan perkembangan budaya populer yang memesat, terlebih lagi media massa yang mendukung penyebaran budaya tersebut. Dengan demikian, mengkonsumsi dan menjadi seseorang ditengah tengah budaya populer sudah menjadi hal yang biasa di Amerika.

Dari lirik lagu pada Bait 1 di atas, menggambarkan bahwa perjalanan untuk mencapai popularitas adalah hal yang sangat menarik dan dapat memotivasi masyarakat khususnya anak remaja di Amerika. Sejak sekolah, hampir seluruh sekolah di amerika serikat memiliki budaya prom night, di mana seluruh siswa-siswi ingin tampil indah agar terpilih untuk menjadi prom queen dan prom king. Prom night adalah kegiatan yang dilakukan oleh anak sekolah SMA pada akhir persekolahan untuk sarana perpisahan, seluruh siswa-siswi tampil secantik dan setampan mungkin. Kegiatan ini dilengkapi dengan dansa yang kemudian pada akhir acara akan terpilih prom queen dan prom king. (Rahayu, 2014).

Pada dasarnya ini sudah menjadi kebiasaan masyarakat Amerika, untuk menjadikan seseorang sorotan publik dari penampilan mereka. Namun, penampilan bukan segalanya, tanpa adanya kerja keras dan percaya diri, keeksistensian akan hilang tenggelam oleh waktu. Untuk menjadi pusat perhatian ternyata sudah menjadi budaya di Amerika sejak masih duduk di bangku sekolah.
Mayoritas masyarakat Amerika cenderung memiliki mimpi untuk sukses dalam hidupnya. Amerika adalah negara yang maju, tentunya masyarakatnya memiliki cara nya sendiri untuk sukses. Rahasia negara Amerika yang maju adalah masyarakat yang memuiliki etos kerja yang baik. Meskipun Amerika adalah negara yang sudah maju, masyarakat Amerika memiliki sifat untuk mementingkan etos kerja. Menurut mereka rahasia sukses adalah untuk selalu bekerja keras dan bersungguh-sungguh. Ketika bekerja keras dan bersungguh-sungguh maka kesuksesan akan tercapai. (Donald, 2007).

Bukti nyata Negara Amerika adalah negara yang hegemoni yang memiliki pengaruh kepada dunia internasional dan memiliki power untuk mengkontrol dunia.

Berdasarkan tentang apa yang telah dijelaskan di atas, hal ini dapat memberi pengaruh bagi masyarakatnya yang cenderung ingin memiliki power dan memiliki sifat pekerja keras untuk sukses. Maka dari itu keberhasilan adalah penting. Orang yang berhasil akan lebih memiliki power dan pada konteks ini adalah power di dalam duna publik figur. Berbicara tentang keberhasilan yang mengacu kepada pencapaian dalam hidup, seringkali dalam tahta dan harta. Maka keberuntungan dan hidup mewah cenderung menjadi hal yang didambakan. Pencapaian popularitas adalah juga sebuah keberhasilan. Aktifitas publik figur cenderung menjadi tontonan yang memacu rasa ingin berhasil, pada kasus ini adalah berhasil mencapai popularitas. Lalu, hadirnya Paparazzi juga memberikan esensi yang lebih bagi publik figur di Amerika Serikat. KBBI mengartikan Paparazzi sebagai juru foto bayaran yang memburu para selebriti.

Paparazzi adalah sekelompok reporter yang bertugas dijalanan untuk memotret kehidupan artis di Amerika secara diam diam maupun terbuka. Para artis terkdang merasa seperti 'dipergunakan' oleh media. Seperti yang tertera pada bait IV kalimat terakhir dan kalimat di bait $\mathrm{V}$.

Dengan analisis yang telah dilakukan dengan melihat unsur tanda dari penanda dan petanda dan hubungan dari tanda tersebut dapat dilihat bahwa, lirik "The Lucky One" adalah bahasa yang cenderung parole karena mengikuti perkembangan zaman. Seperti penyebutan "got the hell out" adalah gaya bahasa modern yang dikembangkan melalui sosial. Kemudian juga pendekatan bahasa melalui konten yang diberikan juga cerita masa kini. Jika kita 
memutuskan bahwa bahasa tersebut adalah bahasa sosial, maka bahasa cenderung diakronik.

Namun, jika kita melihat kembali ajaran saussure. Saussure percaya bahwa meskipun bahasa cenderung parole dan diakronik, sebenarnya bahasa tersebut tetaplah langue dan sinkronik. Karena dengan penyebutan bahasa yang dilakukan masyarakat setiap hari. Bahasa tersebut kemudian akan menjadi sebuah bahasa yang baku.

\section{SIMPULAN}

Terdapat 15 tanda kalimat yang menunjukan tanda populatitas maka, yang memiliki makna: Ketenaran, kemewahan, Publikasi, kekayaan, kesuksesan, Cantik dan keren, dikagumi, dianggap beruntung namun pada akhirnya yang populer merasa dimanfaatkan, dapat tergantikan, bingung, kesepian dan tidak beruntung.

\section{DAFTAR PUSTAKA}

Cresswell. (2015). Penelitian kualitatif \& Desain Riset Memilih Di antara Lima Pendekatan. Yogyakarta: Pustaka Pelajar.

Donald. (2007). Alasan Lain Mengapa Amerika Maju Etos Kerja. Diakses dari http://www. gayahidupdigital.com/2007/11/17/alasanlain-mengapa-amerika-maju-etos-kerja/

Djajeng, M., G. R, S (2013). Young Divas. Jakarta: Rexa Pustaka.

HC. I. (2015). Kebudayaan Amerika. Diperoleh dari Hegemoni Dunia. Diakses dari http:// www.academia.edu/8649443/representasi imperialis ME_BUDAYA_AMERIKA_DALAM_ KOREAN_WAVE_Studi_Semiotika_UnsurUnsur_Western_dalam_Musik_Video_Girls_ Generation_.

Kaparang, M. O, (2013). Analisa Gaya Hidup Remaja Dalam Mengimitasi Budaya Pop Korea Melalui Televisi (Studi pada siswa SMA Negeri 9, Manado), 2,(2). Skripsi, tidak diterbitkan.

KBBI. (n.d). Kamus Besar Bahasa Indonesia Online. Diperoleh dari www.kbbi.web.id.

Mulyana, D. (2007). Ilmu Komunikasi Suatu Pengantar. Bandung: PT Remaja Rosdakarya.

Nafisah, D. (2014). Representasi Imperialisme Budaya Amerika Dalam Korean Wave (Studi Semiotika Unsur-Unsur Western dalam Musik). Skripsi, tidak diterbitkan.
Noverina, A. (2015). A to Z T-Swift Pedia. Jakarta: Gramedia Widiasarana.

Rahayu, S.A. (2014). Asal Muasal Prom Night. Diakses dari http://news.okezone.com/ $\mathrm{read} / 2014 / 05 / 11 / 560 / 983429 /$ asal-muasalprom-night

Hidayat, S.R. (1988). Pengantar Linguistik Umum. Yogyakarta: UGM Press.

Williams, R. (1983). Keywords: A Vocabulary of Culture and Society. London: Fontana. 